\title{
Characterization of a modified ROCK2 protein that allows use of N6-ATP analogs for the identification of novel substrates
}

\author{
Amber L Couzens ${ }^{1,2}$, R Montgomery Gill ${ }^{1}$ and Michael P Scheid ${ }^{1 *}$
}

\begin{abstract}
Background: The Rho-associated coiled-coil kinase-2 (ROCK2) is an important signaling transducer in the transmission of extracellular signals effecting organization of the actin cytoskeleton. ROCK2 has been implicated in numerous pathologies and the current focus is on understanding the molecular events that couple ROCK2 activity to biological function. To aid in the search for new ROCK2 substrates, we have developed an analog-sensitive (AS) ROCK2 protein that allows the use of selective ATP analogs that are not efficiently utilized by other protein kinases.

Results: The analog sensitive protein, M160A ROCK2, was highly active and could phosphorylate proteins from a cellular homogenate with $\gamma^{32} \mathrm{P}_{-} \mathrm{N}_{6}$ (benzyl)ATP. We show the utility of this approach by identifying a putative ROCK2 substrate, elongation initiation factor-1-a1. We further show that the major site of ROCK2 phosphorylation of EIF1a1 is $\mathrm{Thr}^{432}$.
\end{abstract}

Conclusions: Our work demonstrates that AS-ROCK2 could be useful in a systematic proteomic approach for identifying novel ROCK2 substrates.

Keywords: ROCK2, Protein kinase, Chemical engineering, Cell signaling

\section{Background}

The Rho-associated coiled-coil kinase-2 (ROCK2) is a large serine/threonine kinase that plays diverse roles in the cell including contraction, motility and morphology (reviewed in [1]). In the absence of Rho-GTP, ROCK2, and its closely related homologue ROCK1, adopts an auto-inhibited form [2], and upon Rho-GTP binding autoinhibition is relieved and the kinase adopts an open, active conformation [3]. Rho-GTP activates ROCK2 to alter the activity of the actin reorganization machinery. For example, ROCK2 activation indirectly increases myosin light chain (MLC) phosphorylation, through the phosphorylation and inactivation of MLC phosphatase (MLCP) [4]. ROCK2 can also directly phosphorylate MLC at $\operatorname{Ser}^{19}$ [5], the same site targeted by MLC kinase. ROCK2 further causes the disruption of the head-to-tail association of ERM proteins, through the phosphorylation of ezrin, radixin and moesin

\footnotetext{
* Correspondence: mscheid@yorku.ca

${ }^{1}$ Department of Biology, York University, 4700 Keele Street, Toronto, ON M3J1P3, Canada

Full list of author information is available at the end of the article
}

[6]. In addition, LIM-kinase 2 is activated by ROCK2, which then phosphorylates its downstream target, cofilin [7]. Phosphorylation of cofilin inhibits its actin depolymerizing function, thus increasing the number of actin filaments and leads to reorganization of the cytoskeleton [8].

Many human cancers demonstrate increased ROCK2 activity, which can augment tumor invasiveness $[9,10]$. Animal models have revealed that ectopic ROCK2 activation in established tumors is sufficient to drive metastasis of tumor cells into the surrounding stroma [9]. ROCK2 has also been implicated in the pathogenesis of hypertension, since ROCKs play a crucial role in smooth muscle contraction [11], through phosphorylation of MLC and MLCP. Furthermore, ROCK2 has been shown to influence the expression of genes that are important in vascular function, such as plasminogen activator inhibitor-1 (PAI-1) [12] and osteopontin [13]. Since ROCK2 plays a role in a number of human diseases, this kinase has received considerable interest as a potential therapeutic target.

ROCK2 is a member of the AGC kinase family and shares homology within the catalytic domain with other 
AGC kinase members including PKA, PKB, PKC, S6K, and SGK. This has led to the realization that ROCK2, like other AGC kinases, could target sequences that fall within a characteristic phosphorylation motif of R/KXS/ $\mathrm{T}$ or $\mathrm{R} / \mathrm{KXXS} / \mathrm{T}$ [14]. Substrate preference for ROCK2 phosphorylation of this consensus motif is likely governed by spatial and temporal constraints; for example PKA distinguishes bona fide substrates through a mechanism in which bridging between kinase and substrate is provided by adapter and scaffold molecules [15].

To identify new ROCK2 substrates, a potentially useful approach is to modify the kinase so that it utilizes an ATP molecule restricted from use by other kinases. For example, an ATP with a bulky hydrophobic group attached to the $\mathrm{N}_{6}$ position of the purine base prevents entry of the analog into the catalytic site of most protein kinases [16,17]. The kinase domain can be engineered to accept this analog by introducing a modification to sterically accommodate the ATP analog. This chemical engineering approach was first demonstrated in the prototypical protein tyrosine kinase v-Src [17] and has been adapted to various kinases leading to the discovery of many important new substrates $[18,19]$.

Here, we have adapted this chemical engineering approach to ROCK2. We show that a modified ROCK2 harboring a single amino acid substitution in the catalytic domain resulted in a 100-fold decrease in the $K_{m}$ for $\mathrm{N}_{6}$ (Benzyl)ATP utilization compared with wildtype kinase. Phosphorylation of a cellular homogenate with $\gamma^{32} \mathrm{P}-\mathrm{N}_{6}$ (Benzyl)ATP led to a mixture of highly phosphorylated proteins that were separated by 2D-gel electrophoresis. Mass spectral identification and biochemical analysis of one of these phosphorylated proteins, eukaryotic elongation factor-1- $\alpha-1$ (eEF1 $\alpha 1$ ), demonstrated the utility of this approach and provides an important reagent for the future identification of ROCK2 signaling targets.

\section{Results and discussion}

\section{Generation of AS-ROCK2}

We were interested in identifying ATP binding-pocket mutations within ROCK2 that permitted the use of bulky ATP analogs. To screen for these mutations, we developed an in vitro nonradioactive assay based on phosphorylation of a biotinylated ROCK2 substrate peptide matching the consensus ROCK2 phosphorylation site in LIMK. Following phosphorylation in vitro by ROCK2, the biotinylated LIMK peptides were bound to a 96 well streptavidin-coated plate and phosphorylation was measured by probing with a commercially available phospho-specific antibody coupled to a secondary antibody conjugated to an $680 \mathrm{~nm}$ wavelength fluorochrome (IRDye680). Detection of the phospho-peptide antibody complex was performed directly on-plate using the Licor Odyssey infrared laser scanner. The assay was simple, rapid, and had a wide dynamic range comparing phospho$\mathrm{Thr}^{505}$ LIMK fluorescence with the non-phosphorylated LIMK peptide (Figure 1). The unphosphorylated peptide was unreactive to the phosphospecific antibody up to the maximal concentration tested of $4 \mu \mathrm{g} / \mathrm{ml}$.

For ROCK2, Met ${ }^{160}$ is analogous to $\mathrm{Ile}^{338}$ in $\mathrm{v}$-Src (Figure 2A), where this single bulky residue of $\mathrm{v}$-Src was shown to prevent the acceptance of N6-modified ATP analogues [20]. Mutation of the Met ${ }^{160}$ residue in ROCK2 to an alanine or glycine was modeled to yield the space required to accommodate N6(Benzyl)ATP. This mutation was introduced into the W1161A ROCK2 background as we have previously shown that this protein exhibits high kinase activity levels [21]. The Met ${ }^{160}$ to Ala substitution resulted in a 4-fold increase in substrate phosphorylation over wildtype ROCK2 at an $\mathrm{N}_{6}$ (Benzy)ATP concentration of $100 \mu \mathrm{M}$ (Figure 2B). The Met ${ }^{160}$ to Gly substitution had a $50 \%$ reaction velocity compared with the wildtype sequence, while $\mathrm{Met}^{135}$ to $\mathrm{Val}^{135}$ substitution also resulted in a major decrease in reaction velocity, indicating that these substitutions are inhibitory.

Since the $\mathrm{Met}^{160}$ mutation resulted in a greater velocity at $100 \mu \mathrm{M} \mathrm{N} \mathrm{N}_{6}$ (Benzy)ATP than wildtype ROCK2, we analyzed this protein over a concentration range of analog to estimate $K_{m}$ for $\mathrm{N}_{6}$ (Benzyl)ATP. We saw no difference in the $K_{m}$ concentration of ATP between

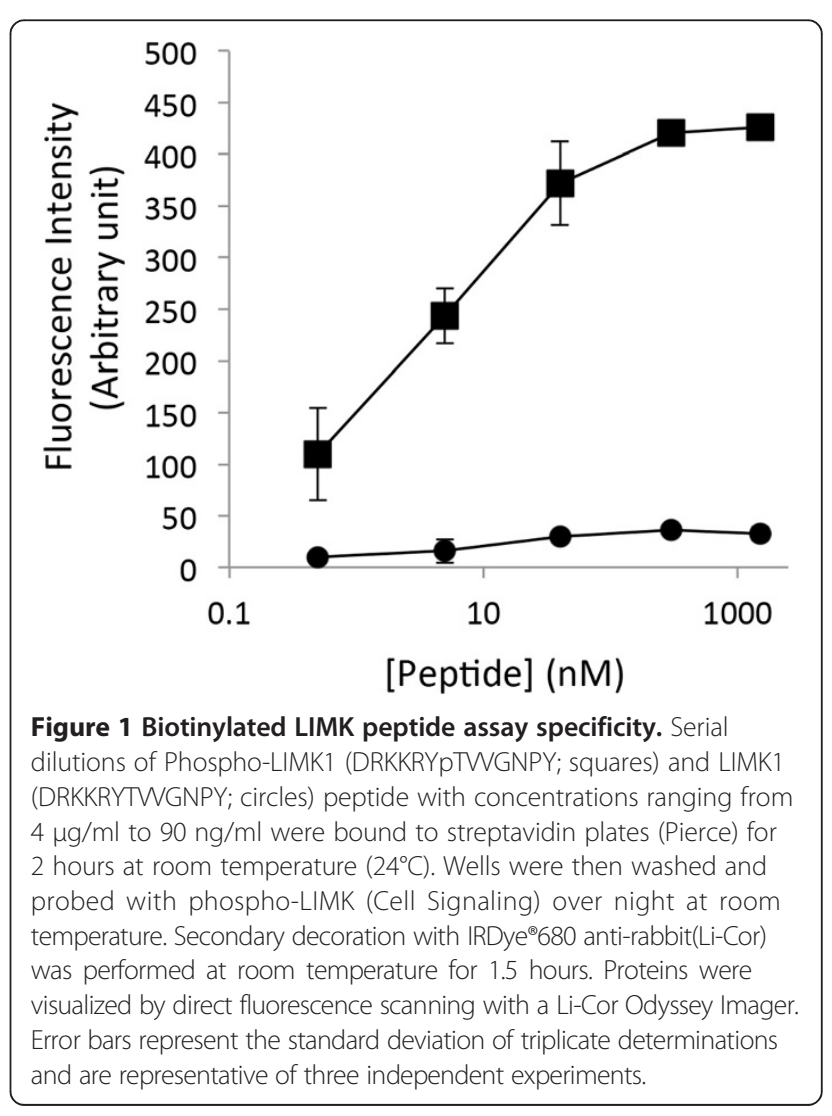



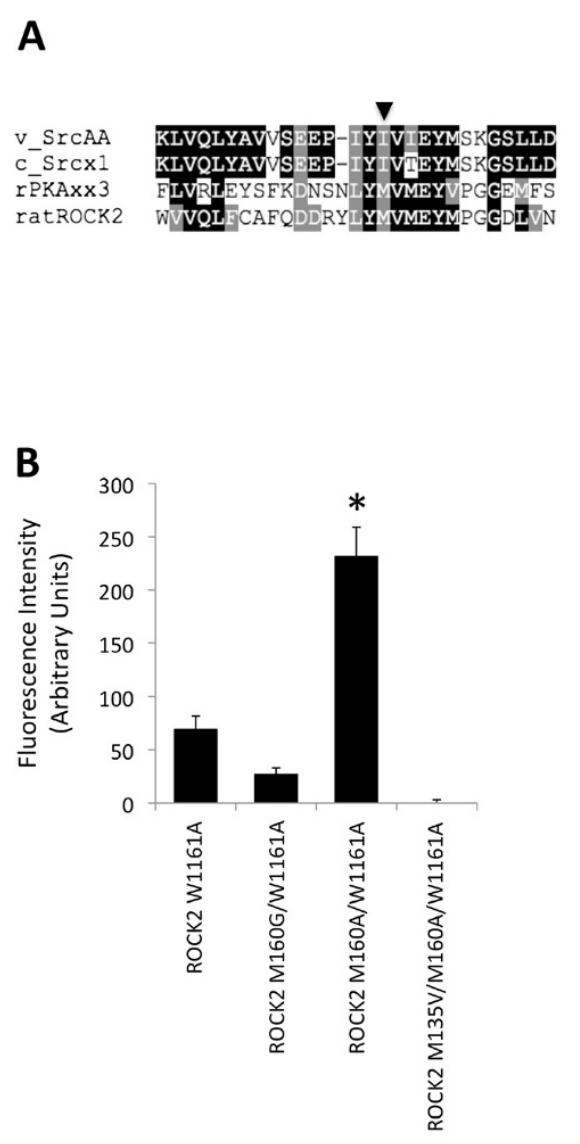

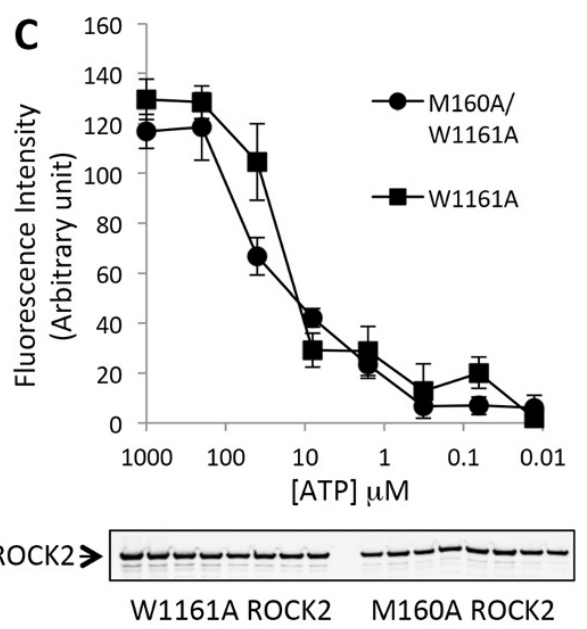

D

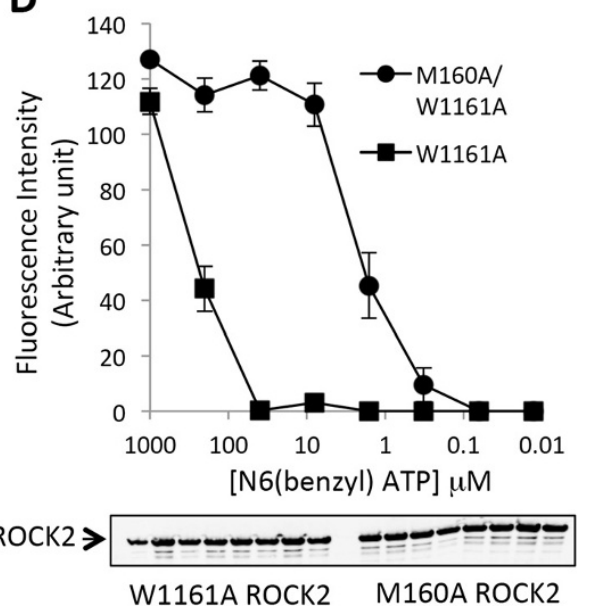

Figure 2 Creation of AS-ROCK2. A. ROCK2, V-Src, C-Src and rat PKA sequences were aligned using ClustalW. The V-Src 'gatekeeper' residue within the ATP-binding pocket is $11 \mathrm{e}^{338}$ (indicated by arrow) and is primarily responsible for restricting the ability of protein kinases from utilizing N6-substiuted ATP analogues. II ${ }^{338}$ in v-Src corresponds to Met ${ }^{160}$ in ROCK2. B. HEK 293 cells were transfected with various FLAG-ROCK2 constructs where indicated. The following day, cells were lysed and ROCK2 was immunoprecipitated with anti-FLAG conjugated agarose. LIMK peptide was phosphorylated using $\mathrm{N}_{6}($ Benzyl)ATP, loaded onto streptavidin plates (Pierce), and probed with P-LIMK (Cell Signaling) overnight at room temperature. Secondary decoration with IRDye ${ }^{\oplus} 680$ anti-rabbit (Li-Cor) was performed at room temperature for 1.5 hours. LIMK peptide phosphorylation was visualized by direct fluorescence scanning with a Li-Cor Odyssey Imager. The relative LIMK phosphorylation signal is shown by the histogram for each ROCK2 mutation. Error bars represent standard deviation of triplicate determinations from three independent experiments. Asterisks indicate significant difference $(P<0.001)$ with W1161A ROCK2 as using Student's $t$-test. C. Kinase activity of W1161A ROCK or W1 161A/M160A ROCK2 was determined as in $B$, using serial dilutions of ATP with concentrations ranging from $1 \mathrm{mM}$ to $12.8 \mathrm{nM}$. D. As in C, except $\mathrm{N}_{6}($ Benzyl)ATP was used. For $C$ and $D$, error bars represent the range of duplicate determinations. Results are representative of three independent experiments.

wildtype ROCK2 and Ala ${ }^{160}$ ROCK2 (both $~ 30 \mu \mathrm{M}$, which is similar to the published $\mathrm{K}_{\mathrm{m}}$ for ROCK2) (Figure 2C). In contrast, there was a 100 -fold decrease in $\mathrm{K}_{\mathrm{m}}$ for $\mathrm{N}_{6}$ (Benzyl)ATP between the two kinases $\left(\sim 200 \mu \mathrm{M}\right.$ for wildtype ROCK2 and $\sim 2 \mu \mathrm{M}$ for Ala ${ }^{160}$ ROCK2) (Figure 2D).

\section{eEF1a1 is phosphorylated by AS-ROCK2 in vitro}

Next, we utilized M160A/W1161A ROCK2 to phosphorylate HEK293 cellular homogenate. Cellular homogenate was incubated with M160A/W1161A ROCK2 in the presence $\gamma^{32} \mathrm{P}-\mathrm{N}_{6}$ (Benzyl)ATP (Figure 3A). In addition to autophosphorylated ROCK2, numerous other ${ }^{32} \mathrm{P}$ labeled proteins were clearly observed by autoradiography. The phosphorylated protein homogenate was then fractionated by $2 \mathrm{D}$-electrophoresis and Figure $3 \mathrm{~B}$ shows that at least eight proteins were phosphorylated by the exogenous M160A/W1161A ROCK2 protein. Two spots in particular were labeled strongly ( $A$ and $B$; Figure $3 \mathrm{~B}$ ), and one of them $(B)$ was identified by mass spectroscopy to be the eukaryotic elongation initiation factor-1- $\alpha 1$ (eEF1 $\alpha 1)$. 


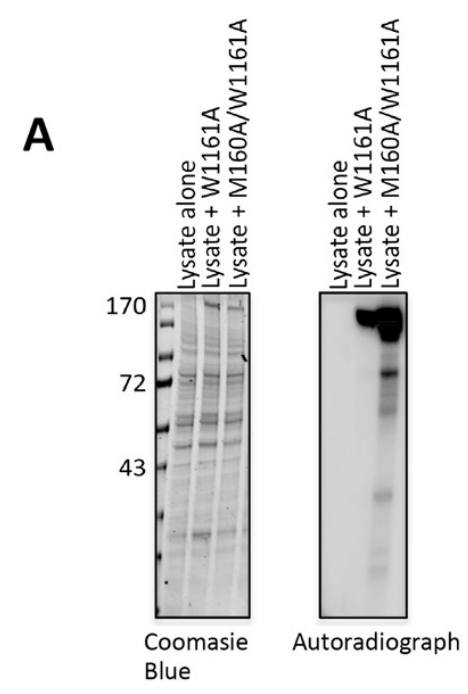

B
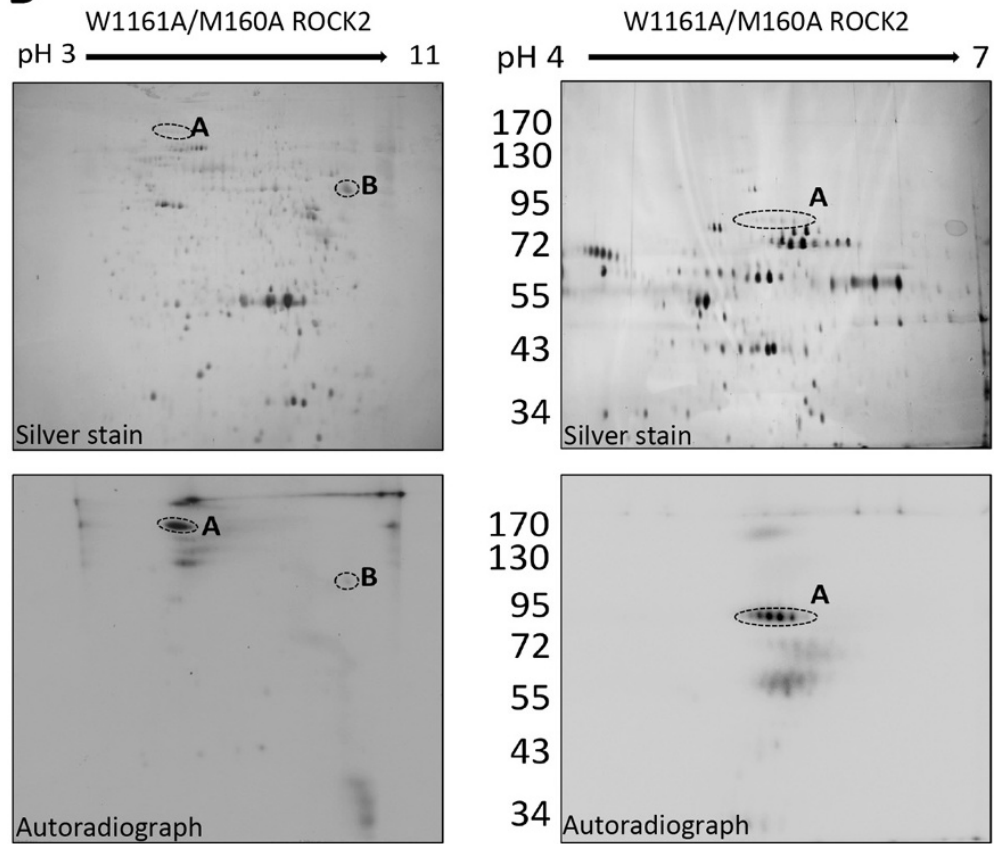

Figure 3 Two-Dimensional separation of ROCK2-phosphorylated HEK293 cellular homogenate. A. HEK 293 cells were transfected with either W1161A or M160A/W1161A ROCK2. The following day, ROCK2 was immunoprecipitated and resuspended in HEK 293 cellular homogenate $(60 \mu \mathrm{g})$ with $\mathrm{Y}^{32} \mathrm{P}-\mathrm{N}_{6}\left(\right.$ Benzyl)ATP in activation buffer for 30 minutes at $30^{\circ} \mathrm{C}$. A small sample was taken and separated by SDS-PAGE followed by staining with Coomassie Blue and exposure to film. B. The remaining sample of M160AW1161A ROCK2-phosphorylated homogenate was separated from the beads and proteins were precipitated with acetic acid/TCA, and then resuspended in 2D sample buffer. Proteins were loaded onto pH 3-11 NL or $\mathrm{pH}$ 4-7 L IEF strips, as indicated. Following overnight IEF, the samples were separated in the $2^{\text {nd }}$ dimension by $8 \%$ SDS-PAGE. Gels were then silver-stained, dried (upper panel), and exposed to Amersham Hyperfilm (lower panel). Dashed circles indicate putative ROCK2 substrates that were excised and sent for identification. Results are representative of three independent experiments.

We noted three sites of eEF1 $\alpha 1\left(\mathrm{Ser}^{53}, \mathrm{Thr}^{72}\right.$, and $\mathrm{Thr}^{432}$ ) that fell within the ROCK consensus phosphorylation motif. These residues were exchanged for alanine and subjected to an in vitro kinase assay with W1161A ROCK2 (Figure 4). Thr ${ }^{432}$ substitution of eEF1 $\alpha 1$ resulted in a $90 \%$ loss of phosphorylation, suggesting that $\mathrm{Thr}^{432}$ is a major site of phosphorylation by ROCK2.
The identification of new ROCK2 substrates is important for understanding how this essential regulator of cell mobility and contraction signals to control cellular events. Our study has provided a number of useful advancements in this regard. First, the biotinylated LIMK peptide assay was developed to quickly and quantitatively assess ROCK2 activity in vitro with phospho-specific 


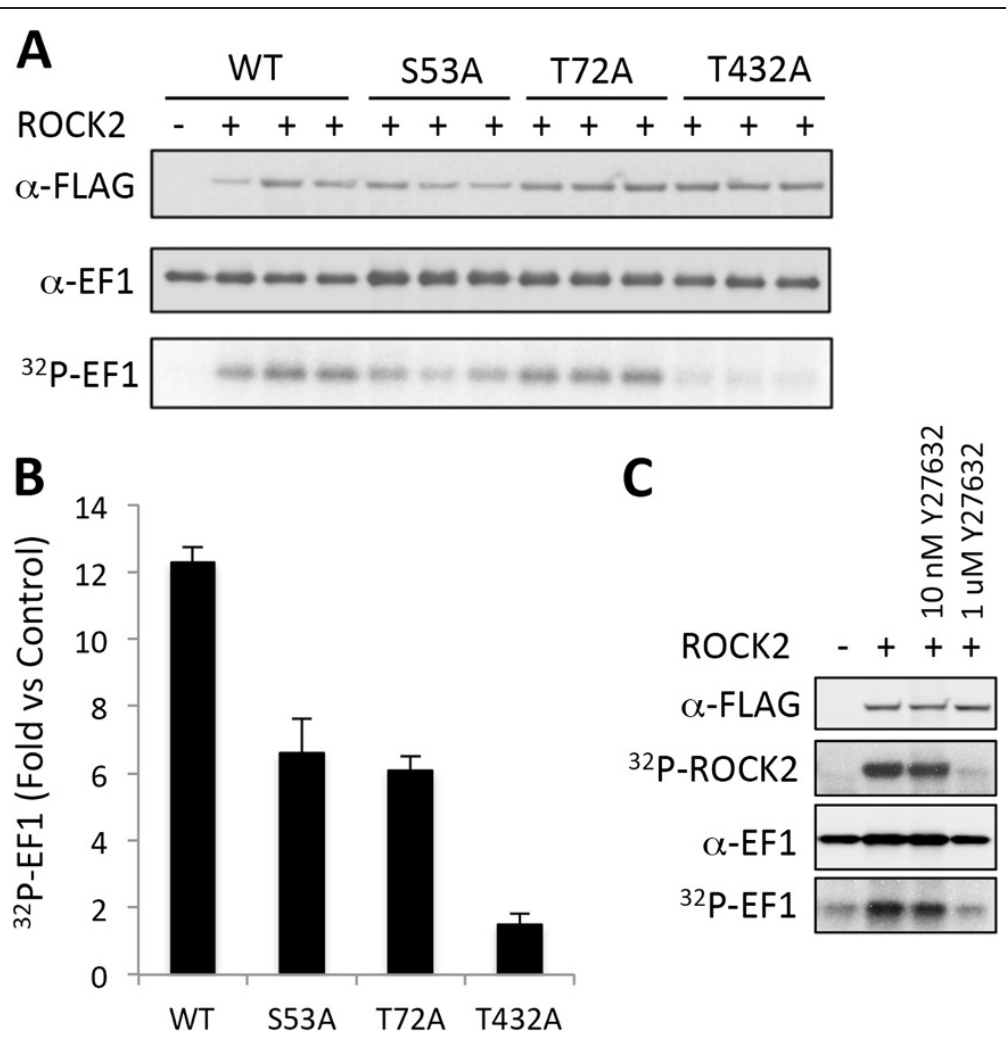

Figure 4 Phosphorylation of EF1a1 in vitro by ROCK2. A. EF1a1 $(5 \mu \mathrm{g})$ was phosphorylated in vitro with W1161A ROCK2 as described in Methods. The samples were then separated by SDS-PAGE and transferred to a PVDF membrane. FLAG-ROCK2 was visualized by blotting with anti-FLAG M2 antibody, and EF1a1 was detected by anti-EF1a1 antibody. EF1a1 phosphorylation was visualized by phosphoimager. B. Fold increase in phosphorylation of EF1a1 by W1161A ROCK2 compared with no kinase for each of the Ser/Thr to alanine substitutions. Error bars represent the standard deviation of triplicate determinations from two independent experiments. C. EF1a1 was phosphorylated in vitro by W1161A ROCK2 in the presence of $10 \mathrm{~nm}$ or $1 \mu \mathrm{M}$ Y27623. The figure is representative of two experiments.

antibodies and without radioactivity. The biotinylated LIMK peptide assay could be useful in future research applications that seek to assess ROCK2 catalytic activity in vitro, such as testing the catalytic effects of point mutations or the discovery of small compound inhibitors of ROCK2.

Secondly, we have utilized the biotinylated LIMK peptide assay to evaluate a ROCK2 mutation that allows utilization of $\mathrm{N}_{6}$ (Benzyl)ATP. Since this bulky ATP ana$\log$ is not efficiently used by ROCK2 $\left(\mathrm{K}_{\mathrm{m}}\right.$ of $200 \mu \mathrm{M}$; Figure 2D) or many other protein kinases $[17,18]$, the M160A ROCK2 protein represents a valuable tool for the future identification of novel ROCK2 substrates. This modified protein was able to phosphorylate the LIMK peptide in vitro, and was able to phosphorylate an array of proteins in a cellular lysate that could be separated by two-dimensional electrophoresis and identification by mass spectroscopy. This resulted in the successful identification of the putative ROCK2 substrate eukaryotic elongation initiation factor- $1 \alpha-1$ (eEF1 $\alpha 1)$. The eEF $1 \alpha 1$ is a highly conserved GTP-binding protein that interacts with aminoacyl-tRNA and recruits it to the ribosome during peptide elongation [22]. In addition to this role, eEF1 $\alpha 1$ has also been found to be a part of a diverse number of cellular activities, including interactions with actin [23] mitotic apparatus complex formation [24], association with phosphorylated PKB [25], and interactions with PDK1 [26].

Izawa and colleagues reported that eEF1 $\alpha$ phosphorylation inhibited co-sedimentation with F-actin [27]. eEF1 $\alpha$ binds F-actin or aminoacyl-tRNA in a competitive manner [28]. Thus, eEF1 $\alpha$ phosphorylation by ROCK may release the elongation factor from the cytoskeleton, allowing binding of aminoacyl-tRNA, leading to localized translation [27]. Other studies have since shown that overexpression of eEF $1 \alpha 2$ leads to filopodia formation in human breast cancer cells, which was reversed with the ROCK2 inhibitor Y-27632 [29]. These results argue that further investigation is required to elucidate whether eEF1 $\alpha 1$ represents a physiological ROCK2 substrate.

Examination of the eEF1 $\alpha 1$ protein sequence revealed that residues $\mathrm{Ser}^{53}, \mathrm{Thr}^{72}$, and $\mathrm{Thr}^{432}$ all fall within a ROCK2 consensus motif R/KXS/T or R/KXXS/T 
(where $\mathrm{X}$ is any amino acid) [14]. Individual mutation of these residues to alanine followed by in vitro phosphorylation by ROCK2 showed that $\mathrm{Thr}^{432}$ is the major site of ROCK2 phosphorylation, since minimal phosphorylation was observed with T432A eEF1 $\alpha 1$ (Figure 4). Future work will involve the generation of a phospho-specific antibody to $\mathrm{Thr}^{432}$ of eEF $1 \alpha 1$ that will aid in elucidating the role of phosphorylation at this residue in cells.

Amano and colleagues [30] have previously reported an alternative proteomic approach to identify substrates of ROCK2, by combining mass spectrometry with affinity column chromatography. This method utilized the catalytic domain of ROCK2 as bait to probe a fraction of cytosol for interacting proteins [30], where our ATP analogue approach relies on a full-length protein that specifically phosphorylates substrates. Both techniques are similar in that proteins of interest were first separated from non-substrates, followed by identification by mass spectrometry.

Further identification of ROCK2 substrates using the ATP analogue approach will focus on specifically enriching for proteins phosphorylated by the AS-ROCK2 protein. This could be achieved by utilizing an $\mathrm{N}_{6}-\mathrm{ATP}-\gamma-\mathrm{S}$ analogue and substrate enrichment with iodoacetylagarose resin, which binds the sulfonated group [31], prior to identification by mass spectrometry.

\section{Conclusion}

In summary, our work has shown the utility of an ASROCK2 mutation that allows the use of bulky ATP analogs. This model will be of significant value for future efforts aimed at identifying novel ROCK2 substrates that could play a role in human disease such as cancer and hypertension.

\section{Methods \\ Cell culture}

HEK (human embryonic kidney)-293 cells were obtained from the A.T.C.C. (Manassas, VA, U.S.A.) and cultured in DMEM (Dulbecco's modified Eagle's medium) supplemented with $10 \%$ fetal bovine serum and antibiotics at $37^{\circ} \mathrm{C}$ in a humidified incubator containing $5 \% \mathrm{CO} 2$.

\section{Reagents}

Antibodies used were anti-FLAG M2 (Sigma-Aldrich), anti-[phosphoLIMK1 $\left(\mathrm{Thr}^{508}\right) / \mathrm{LIMK2}\left(\mathrm{Thr}^{505}\right)$ ] (Cell Signaling Technology) and anti-EF1 $\alpha 1$ (H-300) (Santa Cruz Biotechnology).

\section{Site-directed mutagenesis}

The M160A/W1161A and M160G/W1161A ROCK2 were generated using QuikChange ${ }^{\circ}$ mutagenesis kit (Stratagene). Mutations were sequence-verified.

\section{cDNA transfections}

HEK-293 cells were plated onto $100-\mathrm{mm}$ dishes at $80 \%$ confluence and transfected with $2.5 \mathrm{mg}$ of cDNA using Lipofectamine ${ }^{\text {tw }} 2000$ (Invitrogen) following the manufacturers protocol. 4 hours post transfection, the medium was removed and replaced with DMEM containing fetal bovine serum.

\section{Cell lysis}

Cells were lysed in radioimmunoprecipitation (RIPA) buffer, containing $10 \mathrm{mM}$ sodium phosphate ( $\mathrm{pH}$ 7.4), $150 \mathrm{mM} \mathrm{NaCl}, 0.1 \%(\mathrm{w} / \mathrm{v})$ SDS, $1 \%(\mathrm{v} / \mathrm{v})$ Triton X100, $0.25 \%(\mathrm{w} / \mathrm{v})$ deoxycholate, $5 \mathrm{mM}$ EDTA, $25 \mathrm{mM} \mathrm{NaF}$, $25 \mathrm{mM}$ 2-glycerolphosphate, $200 \mu \mathrm{M} \mathrm{Na} \mathrm{VO}_{4}$ and protease inhibitors.

\section{Biotinylated LIMK1 peptide assay}

FLAG-tagged ROCK2 was immunoprecipitated from transfected cell lysates with M2 monoclonal antibody conjugated to agarose (Sigma-Aldrich). Immunoprecipitates were washed three times in RIPA buffer, followed by an additional three times in activation buffer containing $(50 \mu \mathrm{M}$ Tris- $\mathrm{HCl}, 0.1 \mathrm{mM}$ EGTA, $0.1 \% 2-$ mercaptoethanol), and finally resuspended in $30 \mu \mathrm{l}$ of activation buffer containing various concentrations of ATP or $\mathrm{N}_{6}$ (Benzyl)ATP. Biotinylated (N-terminal) LIMK1 peptide (DRKKRYTVVGNPY) was used as a substrate $(200 \mu \mathrm{M})$. Samples were incubated for $30 \mathrm{~min}$ at $30^{\circ} \mathrm{C}$, the reaction was terminated by the addition of $7.5 \mathrm{mM}$ EDTA. The samples were then loaded onto streptavidin plates (Pierce) and bound for 2 hours at room temperature $\left(24^{\circ} \mathrm{C}\right)$. The plates were then probed with phospho-LIMK (Cell Signaling) overnight at room temperature. Secondary decoration with IRDye 680 anti-rabbit (Li-Cor) was performed at room temperature for 1.5 hours. Proteins were visualized by direct fluorescence scanning with a Li-Cor Odyssey Imager.

\section{Cellular homogenate labeling}

$3 \times 10^{6}$ HEK293 cells were lysed in $2 \mathrm{ml}$ hypotonic lysis buffer (20 mM Hepes, pH 7.4, $2 \mathrm{mM} \mathrm{MgCl} 2,200 \mu \mathrm{M}$ Na3VO4, $0.25 \% \mathrm{NP}-40$, and protease inhibitors). Insoluble particulates were removed by centrifugation and $10 \%$ glycerol was added to the supernatant and stored at $-80^{\circ} \mathrm{C}$. Prior to in vitro labeling, the homogenate was heat inactivated for $10 \mathrm{~min}$ at $60^{\circ} \mathrm{C}$. Cellular homogenate was then added to immunoprecipitated ROCK2 proteins with $\gamma^{32} \mathrm{P}-\mathrm{N}_{6}$ (Benzyl)ATP in activation buffer. The reaction was incubated for $30 \mathrm{~min}$ at $30^{\circ} \mathrm{C}$ and terminated by the addition of $2 X$ LDS sample buffer.

\section{Two-dimensional electrophoresis}

Proteins were precipitated from samples with $4 \mathrm{x}$ the volume acetone, $10 \%$ TCA and $20 \mathrm{mM}$ DTT at $-20^{\circ} \mathrm{C}$ for 
$45 \mathrm{~min}$. Proteins were then pelleted by centrifugation at $4^{\circ} \mathrm{C}$ for $15 \mathrm{~min}$. The supernatant was removed and the protein pellet was subjected to an acetone wash, and then dried of residual acetone under vacuum for $2 \mathrm{~min}$. The pellet was then resuspended in $260 \mu \mathrm{l} 2 \mathrm{D}$ sample buffer (7 M Urea, 2 M Thio-Urea, 4\% CHAPS, 2\% DTT, $1 \%$ IPG buffer). To ensure protein solubilization, samples were incubated at room temperature for $15 \mathrm{~min}$ with intermittent vortexing. The sample was then transferred to a fresh Eppendorf tube and $250 \mu \mathrm{l}$ was pipetted into a $13 \mathrm{~cm}$ strip holder (GE Healthcare). An immobiline dry strip (GE Healthcare) was then placed in the holder, overlayed with drystrip cover fluid. Both $\mathrm{pH} 3-$ $11 \mathrm{NL}$ and $\mathrm{pH}$ 4-7 L immobiline dry strips were used, see figures for details.

Proteins were then separated in the first dimension with the following isoelectric focusing (IEF) conditions: 10 hours rehydration, 5 hours $30 \mathrm{~V}, 1$ hour $500 \mathrm{~V}, 1$ hour $1000 \mathrm{~V}, 2.5$ hour $8000 \mathrm{~V}$, and $30 \mathrm{~min} 8000 \mathrm{~V}$ for ph3-11 NL. The conditions for $\mathrm{pH} 4-7$ were as follows: 10 hours rehydration, 5 hours $30 \mathrm{~V}, 1$ hour $500 \mathrm{~V}, 1$ hour $1000 \mathrm{~V}, 2.5$ hours $8000 \mathrm{~V}$, and 0.55 hours $8000 \mathrm{~V}$. Following IEF, strips were removed from the holders and pre-equilibrated in SDS-equilibration buffer $(50 \mathrm{mM}$ Tris-HCl, pH 8.8, 6 M Urea, 30\% glycerol, 2\% SDS, and $10 \mathrm{mg} / \mathrm{ml} \mathrm{DTT})$ for 1 hour at room temperature $\left(24^{\circ} \mathrm{C}\right)$ with rocking. Proteins were then separated in the second dimension with $8 \%$ SDS-PAGE. After electrophoresis, gels were rinsed in ultrapure water and fixed in 50\% ethanol, 10\% acetic acid and stained using the Silver Quest kit (Invitrogen). ${ }^{32}$ P-labeled proteins identified by autoradiography were excised from the gel with a scalpel. Gel fragments were resuspended in $1 \%$ acetic acid in microcentrifuge tubes prior to analysis by mass spectrometry.

\section{EF1a1 in vitro kinase assay}

FLAG-ROCK2 was immunoprecipitated from cell lysates with $20 \mu \mathrm{l}$ of M2 FLAG monoclonal antibody conjugated to agarose (Sigma-Aldrich). Immunoprecipitates were washed three times with RIPA buffer, followed by two additional washes with kinase assay buffer containing $20 \mathrm{mM}$ Tris pH 7.5, $50 \mathrm{mM} \mathrm{NaCl}, 5 \mathrm{mM} \mathrm{MgCl} 2,1 \mathrm{mM}$ dithiothreitol (DTT), and finally resuspended in $30 \mu \mathrm{l}$ of kinase assay buffer containing $10 \mu \mathrm{M}$ ATP and $1 \mathrm{mCi}$ $\left[{ }^{32} \mathrm{P}\right]$ ATP. Purified EF $1 \alpha 1$ proteins were used as substrate. Samples were incubated for $30 \mathrm{~min}$ at $30^{\circ} \mathrm{C}$, and terminated by the addition of $2 x$ LDS sample buffer, and resolved on $4-12 \%$ Criterion $^{\text {tw }} \mathrm{XT}$ precast gel (Bio-Rad Laboratories). ${ }^{32} \mathrm{P}$-EF1 $\alpha 1$ was visualized by phosphoimager (Bio-Rad Laboratories).

\section{Competing interest}

The authors declare that they have no competing interests.

\section{Authors' contributions}

ALC contributed to the design of the study, performed the experiments, interpreted the results, and wrote the initial draft of the manuscript. RMG contributed to the generation of reagents for the study. MPS conceived and contributed to the design of the study, interpreted the results, and edited the final draft of the manuscript. All authors read and approved the final manuscript.

\section{Acknowledgements}

We thank Professor Shuh Narumiya (Department of Cell Pharmacology, Kyoto University Graduate School of Medicine, Kyoto, Japan) for ROCK2 expression vectors. Mass Spectra were provided by the Centre for Research in Mass Spectrometry at York University. Operating funds from the Canadian Institute of Health Research supported this work. The funders had no role in study design, data collection and analysis, decision to publish or preparation of the manuscript.

\section{Author details}

${ }^{1}$ Department of Biology, York University, 4700 Keele Street, Toronto, ON M3J1P3, Canada. ${ }^{2}$ Current Address: Centre for Systems Biology, Lunenfeld-Tanenbaum Research Institute, Mount Sinai Hospital, Toronto, ON M5G 1X5, Canada.

Received: 4 September 2013 Accepted: 7 January 2014

Published: 9 January 2014

\section{References}

1. Riento K, Ridley AJ: Rocks: multifunctional kinases in cell behaviour. Nat Rev Mol Cell Biol 2003, 4(6):446-456.

2. Amano M, Chihara K, Nakamura N, Kaneko T, Matsuura Y, Kaibuchi K: The $\mathrm{COOH}$ terminus of Rho-kinase negatively regulates rho-kinase activity. J Biol Chem 1999, 274(45):32418-32424.

3. Ishizaki T, Maekawa M, Fujisawa K, Okawa K, Iwamatsu A, Fujita A, Watanabe N, Saito Y, Kakizuka A, Morii N, et al: The small GTP-binding protein Rho binds to and activates a $160 \mathrm{kDa}$ Ser/Thr protein kinase homologous to myotonic dystrophy kinase. EMBO J 1996, 15(8):1885-1893.

4. Kawano Y, Fukata Y, Oshiro N, Amano M, Nakamura T, Ito M, Matsumura F, Inagaki M, Kaibuchi K: Phosphorylation of myosin-binding subunit (MBS) of myosin phosphatase by Rho-kinase in vivo. J Cell Biol 1999, 147(5):1023-1038.

5. Totsukawa G, Yamakita Y, Yamashiro S, Hartshorne DJ, Sasaki Y, Matsumura F: Distinct roles of ROCK (Rho-kinase) and MLCK in spatial regulation of MLC phosphorylation for assembly of stress fibers and focal adhesions in 3 T3 fibroblasts. J Cell Biol 2000, 150(4):797-806.

6. Matsui T, Maeda M, Doi Y, Yonemura S, Amano M, Kaibuchi K, Tsukita S: Rho-kinase phosphorylates $\mathrm{COOH}$-terminal threonines of ezrin/radixin/ moesin (ERM) proteins and regulates their head-to-tail association. J Cell Biol 1998, 140(3):647-657.

7. Sumi T, Matsumoto K, Nakamura T: Specific activation of LIM kinase 2 via phosphorylation of threonine 505 by ROCK, a Rho-dependent protein kinase. J Biol Chem 2001, 276(1):670-676.

8. Maekawa M, Ishizaki T, Boku S, Watanabe N, Fujita A, Iwamatsu A, Obinata T, Ohashi K, Mizuno K, Narumiya S: Signaling from Rho to the actin cytoskeleton through protein kinases ROCK and LIM-kinase. Science 1999, 285(5429):895-898.

9. Croft DR, Sahai E, Mavria G, Li S, Tsai J, Lee WM, Marshall CJ, Olson MF: Conditional ROCK activation in vivo induces tumor cell dissemination and angiogenesis. Cancer Res 2004, 64(24):8994-9001.

10. Lane J, Martin TA, Watkins G, Mansel RE, Jiang WG: The expression and prognostic value of ROCK I and ROCK II and their role in human breast cancer. Int J Oncol 2008, 33(3):585-593.

11. Loirand G, Guerin P, Pacaud P: Rho kinases in cardiovascular physiology and pathophysiology. Circ Res 2006, 98(3):322-334.

12. Takeda K, Ichiki T, Tokunou T, lino N, Fujii S, Kitabatake A, Shimokawa H, Takeshita A: Critical role of Rho-kinase and MEK/ERK pathways for angiotensin II-induced plasminogen activator inhibitor type-1 gene expression. Arterioscler Thromb Vasc Biol 2001, 21(5):868-873.

13. Kawamura $H$, Yokote $K$, Asaumi $S$, Kobayashi $K$, Fujimoto M, Maezawa $Y$, Saito $Y$, Mori S: High glucose-induced upregulation of osteopontin is mediated via Rho/Rho kinase pathway in cultured rat aortic smooth muscle cells. Arterioscler Thromb Vasc Biol 2004, 24(2):276-281. 
14. Amano M, Ito M, Kimura K, Fukata Y, Chihara K, Nakano T, Matsuura Y, Kaibuchi K: Phosphorylation and activation of myosin by Rho-associated kinase (Rho-kinase). J Biol Chem 1996, 271(34):20246-20249.

15. Pidoux $G$, Tasken $\mathrm{K}$ : Specificity and spatial dynamics of protein kinase $A$ signaling organized by A-kinase-anchoring proteins. J Mol Endocrinol 2010, 5:271-284

16. Elphick LM, Lee SE, Gouverneur V, Mann DJ: Using chemical genetics and ATP analogues to dissect protein kinase function. ACS Chem Biol 2007, 2(5):299-314.

17. Shah K, Liu Y, Deirmengian C, Shokat KM: Engineering unnatural nucleotide specificity for Rous sarcoma virus tyrosine kinase to uniquely label its direct substrates. Proc Natl Acad Sci USA 1997, 94(8):3565-3570

18. Habelhah H, Shah K, Huang L, Burlingame AL, Shokat KM, Ronai Z: Identification of new JNK substrate using ATP pocket mutant JNK and a corresponding ATP analogue. J Biol Chem 2001, 276(21):18090-18095.

19. Eblen ST, Kumar NV, Shah K, Henderson MJ, Watts CK, Shokat KM, Weber MJ: Identification of novel ERK2 substrates through use of an engineered kinase and ATP analogs. J Biol Chem 2003, 278(17):14926-14935.

20. Liu Y, Shah K, Yang F, Witucki L, Shokat KM: Engineering Src family protein kinases with unnatural nucleotide specificity. Chem Biol 1998, 5(2):91-101.

21. Couzens AL, Saridakis V, Scheid MP: The hydrophobic motif of ROCK2 requires association with the $\mathrm{N}$-terminal extension for kinase activity. Biochem J 2009, 419(1):141-148.

22. Riis $\mathrm{B}$, Rattan $\mathrm{SI}$, Clark BF, Merrick WC: Eukaryotic protein elongation factors. Trends Biochem Sci 1990, 15(11):420-424.

23. Yang F, Demma M, Warren V, Dharmawardhane S, Condeelis J: Identification of an actin-binding protein from Dictyostelium as elongation factor $1 \mathrm{a}$. Nature 1990, 347(6292):494-496.

24. Ohta K, Toriyama M, Miyazaki M, Murofushi H, Hosoda S, Endo S, Sakai H: The mitotic apparatus-associated $51-\mathrm{kDa}$ protein from sea urchin eggs is a GTP-binding protein and is immunologically related to yeast polypeptide elongation factor 1 alpha. J Biol Chem 1990, 265(6):3240-3247.

25. Lau J, Castelli LA, Lin EC, Macaulay SL: Identification of elongation factor 1alpha as a potential associated binding partner for Akt2. Mol Cell Biochem 2006, 286(1-2):17-22.

26. Pecorari L, Marin O, Silvestri C, Candini O, Rossi E, Guerzoni C, Cattelani S, Mariani SA, Corradini F, Ferrari-Amorotti G, et al: Elongation Factor 1 alpha interacts with phospho-Akt in breast cancer cells and regulates their proliferation, survival and motility. Mol Cancer 2009, 8:58.

27. Izawa T, Fukata Y, Kimura T, Iwamatsu A, Dohi K, Kaibuchi K: Elongation factor-1 alpha is a novel substrate of rho-associated kinase. Biochem Biophys Res Commun 2000, 278(1):72-78.

28. Liu G, Tang J, Edmonds BT, Murray J, Levin S, Condeelis J: F-actin sequesters elongation factor 1alpha from interaction with aminoacyl-tRNA in a pH-dependent reaction. J Cell Biol 1996, 135(4):953-963.

29. Amiri A, Noei F, Jeganathan S, Kulkarni G, Pinke DE, Lee JM: eEF1A2 activates Akt and stimulates Akt-dependent actin remodeling, invasion and migration. Oncogene 2007, 26(21):3027-3040.

30. Amano M, Tsumura Y, Taki K, Harada H, Mori K, Nishioka T, Kato K, Suzuki T, Nishioka Y, Iwamatsu A, et al: A proteomic approach for comprehensively screening substrates of protein kinases such as Rho-kinase. PLOS ONE 2010, 5(1):e8704

31. Blethrow JD, Glavy JS, Morgan DO, Shokat KM: Covalent capture of kinasespecific phosphopeptides reveals Cdk1-cyclin B substrates. Proc Natl Acad Sci USA 2008, 105(5):1442-1447.

doi:10.1186/1472-6750-14-2

Cite this article as: Couzens et al: Characterization of a modified ROCK2 protein that allows use of N6-ATP analogs for the identification of novel substrates. BMC Biotechnology 2014 14:2.

\section{Submit your next manuscript to BioMed Central and take full advantage of:}

- Convenient online submission

- Thorough peer review

- No space constraints or color figure charges

- Immediate publication on acceptance

- Inclusion in PubMed, CAS, Scopus and Google Scholar

- Research which is freely available for redistribution

Submit your manuscript at www.biomedcentral.com/submit
C Biomed Central 